\title{
O Pátio das Sombras: a representação da morte na releitura de Mia Couto.
}

O Pátio das Sombras: the representation of death in the re-reading of Mia Couto.

\section{$\underline{\underline{\text { Regina Célia Ruiz }}}$}

1 Doutoranda pelo Programa de Estudos Comparados de Literaturas de Língua Portuguesa da FFLCH-USP. 
RESUMO (RESENHA): COUTO, Mia. O pátio das sombras. Ilustrações de Malangatana, vol. 10. In: Contos de Moçambique, São Paulo: Kapulana, 2018.

ABSTRACT (REVIEW): COUTO, Mia. O pátio das sombras. Ilustrações de Malangatana, vol. 10. In: Contos de Moçambique, São Paulo: Kapulana, 2018.

PALAVRAS-CHAVE: Moçambique; Tradição oral; Morte, Cultura maconde, Mia Couto, Malangatana.

KEYWORDS: Mozambique; Oral tradition; Death, Maconde Culture, Mia Couto, Malangatana. 
Desde 2016, a editora Kapulana vem lançando a série Contos de Moçambique. Uma coletânea que nasceu em parceria com a Escola Portuguesa de Moçambique e a Fundació Contes pel Món, de Barcelona, Espanha. São histórias recontadas por renomados escritores e ilustradores de diversas expressões artísticas. Os livros trazem, para o imaginário infantil, as riquezas e conhecimentos da cultura africana da região moçambicana.

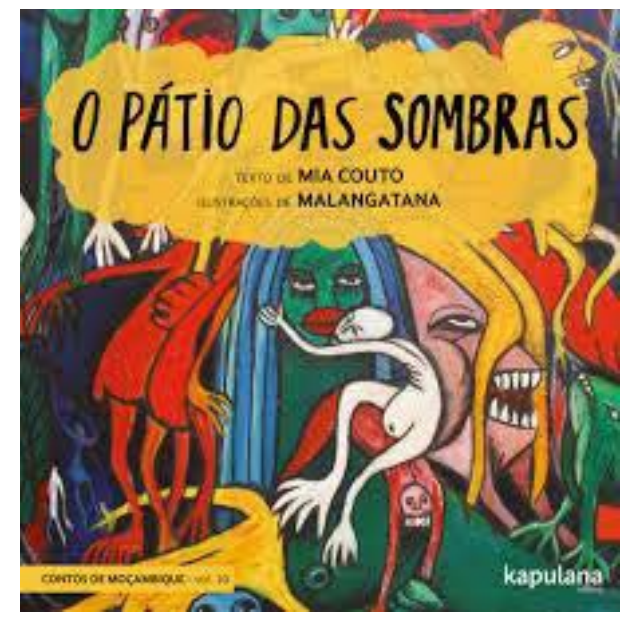

A cultura de um povo é vista pela transmissão de sua história. O povo africano possui a marca das tradições, o culto ao sagrado, o respeito aos antepassados e ao mundo espiritual. Um dos pontos de tensão entre culturas e disparador de mistérios e crenças é a morte. Para algumas crenças, é o fim absoluto; para outras, uma passagem; para o povo maconde, de onde se originou a narrativa "O Pátio das Sombras", os mortos descansam na terra e por ela caminham. Mas, nas palavras de Mia Couto, há uma condição para que os vivos possam estar rodeados pelos que já se foram: "os mortos, quando lembrados, não chegam nunca a morrer" (COUTO, 2018, p.20), e é sobre essa lembrança que trata "O Pátio das Sombras", o $10^{\circ}$ volume da coletânea. As narrativas conhecidas por meio da tradição oral são elementos de fundamental importância na reconstituição e reconhecimento de especificidades históricas do continente africano. São as histórias transmitidas por gerações que trazem a cultura, os ensinamentos, as crenças de um povo.

"O Pátio das Sombras" é uma reescrita de um conto moçambicano originário dos macondes, grupo étnico bantu, do nordeste de Moçambique. O texto foi escrito por Mia Couto, autor consagrado moçambicano, traduzido em mais de 30 idiomas e com importantes prêmios nacionais e internacionais. As ilustrações ficaram por conta de um dos mais importantes artistas de Moçambique, Malangatana.

A narrativa traz a história de uma família que mora em uma aldeia e vive do trabalho do campo. Um dia, ao sair para trabalhar, um dos netos chama a avó para ir junto. E a mulher diz que não vai, pois "sente muito a cabeça". Antes que o garoto se afaste, a avó percebe que ele está usando a pulseira do pai, homem que havia morrido há tempos. 
$\mathrm{E}$ assim, vamos adentrando nessa narrativa com indicações importantes sobre o que está por vir. O espaço do campo, onde se passa a narrativa; a figura da mulher idosa, marca dos ensinamentos africanos quando se fala de tradição oral. Lembramos dos mais velhos como detentores de sabedoria, com a missão de transmitir conhecimentos aos mais jovens e prepará-los para o mundo. Há, também, a presença da morte, representada pela pulseira que era do pai do garoto: "Um arrepio atravessou o menino. Há muito que o pai tinha morrido. Esse arrepio o fez repensar. E ele estendeu o pulso para que a avó lhe retirasse o enfeite.” (COUTO, 2018, p. 7).

A família sai para o campo, deixando a avó. Durante o dia, ouvem barulhos que vêm da região da casa. Parecia uma festa, uma comemoração. O garoto é enviado para ver o que estava acontecendo, mas encontra a avó sozinha, no mesmo lugar. No dia seguinte, aconteceu a mesma coisa, até que a avó lhe confessa que

\footnotetext{
os filhos mortos moravam vivos dentro de sua cabeça. À medida que os filhos iam morrendo, a cabeça começava a tornar-se muito grande. E começou-lhe a pesar muito. Foi a partir daquele momento que deixou de poder sair de casa. Quando ela ficava só, os habitantes da sua cabeça eclodiam: raparigas, mulheres com filhos, homens, rapazes. E festejavam a vida no pátio de casa. A bem dizer, o mundo inteiro se transformava no terreiro de sua casa. (COUTO, 2018, p. 14)
}

A passagem deixa em aberto os possíveis questionamentos sobre a morte. Como quem já morreu pode voltar a existir? Como podem se alegrar, festejar e estar ao redor dos vivos? Aborda-se, aqui, o mistério da morte envolvendo culturas, crenças e religiões.

$\mathrm{Na}$ visão africana, o homem morre sempre no interior da comunidade e os que continuam a viver sobre a terra, vivem a união com os seus mortos, assim, a morte não é o fim de tudo. É só uma passagem deste mundo ao outro mundo invisível. Os mortos não estão mortos, mas continuam a viver num outro mundo em relação com o nosso mundo. (MESSIAS, 2008, p.112). 
Nas culturas moçambicanas, em geral, a morte é vista como continuidade da vida. Os mortos são seres espirituais, mas podem se locomover e conviver com os vivos, sempre objetivando a harmonia.

A narrativa recontada tem, no seu desfecho, uma importante explicação. A avó ensina ao neto um olhar mais ameno sobre a morte, que se dá no momento do sonho: "O menino então entendeu: o sonho era o modo como os falecidos visitavam os vivos e festejavam a Vida". (COUTO, 2018, p. 19). Nesse percurso fantástico, o jovem encontra o pai já falecido, este lhe diz que os mortos nunca saíram de perto do povo da aldeia e alguns choram "porque têm medo de não serem lembrados pelos vivos. Os mortos não morrem quando saem da Vida. Morrem quando são esquecidos.” (COUTO, 2018, p. 18).

O garoto começa a dividir com a avó o grande segredo e detém a responsabilidade de não compartilhá-lo com mais ninguém. A quebra do sigilo poderia deixar os mortos "sem caminho de regresso". A avó torna-se a ligação entre os dois mundos. E há, ainda, a preocupação com a segurança da mulher: "Se alguém descobrisse esse mistério, ela podia ser condenada como feiticeira e podiam mesmo tirar-lhe a vida”. (COUTO, 2018, p. 15).

$\mathrm{Na}$ narrativa original, a cabeça da avó estoura para que quem já morreu saia. Uma multidão a trancou em uma jaula e depois a matou, pois há a crença, nas sociedades rurais, de que mulheres viúvas e velhas transformam-se em feiticeiras e o feitiço é tido como a causa de todos ao males do grupo. Mas Mia Couto optou por modificar o final. "Esses valores devem ser questionados hoje e senti ser necessário reconverter esta história, alterando o seu desfecho" (COUTO, 2018, p.20).

A festa dos familiares falecidos, descrita na narrativa, faz referência a uma manifestação cultural de Moçambique, o Mapiko. Na tradição do povo maconde, um homem mascarado dança ao som de batuque e cantos tradicionais, estabelecendo um elo mágico e sobrenatural com o mundo dos mortos. A identidade do dançarino fica em segredo, pois acredita-se que ali não é o homem que dança, mas sim um espírito. Em "Pátio das Sombras", não há referência a máscaras, mas a festa e a dança dos seres em estado de êxtase e alegria lembram a celebração. "E cantavam, e dançavam e festejavam como se estivessem embriagados "(COUTO, 2018, p. 17)

As ilustrações de Malangatana garantem e reforçam o movimento da narrativa por dialogarem plenamente com a escrita de Mia Couto. O artista usa o nanquim, técnica que se 
originou na China, mas com grande popularidade no Japão. O nanquim é um material usado para a escrita, a pintura e o desenho. As formas zoomórficas dos homens, comprimidos, retorcidos, podem nos fazer pensar nos mortos que saem da cabeça da avó da história, trazendo à tona o universo onírico descoberto pelo neto para adentrar no outro mundo. Malangatana faleceu em 2011, em Portugal.

Percebe-se, assim, uma nova leitura para o conto tradicional. Na linguagem metafórica em que os mortos rodeiam e vivem ao lado dos vivos, Mia Couto propõe uma nova visão, continuando fiel às suas tradições: evoca a lembrança e o respeito aos já falecidos.

Com este volume da coleção, a visão ocidental sobre a morte pode receber novos contornos. O mistério em torno do assunto continua, mas Mia Couto e Malangatana possibilitam a construção de novos olhares, unindo os dois mundos por meio de palavras e formas.

O conto foi lançado no mês de outubro de 2018, em homenagem ao Dia das Crianças, mas, muito além de ser voltado ao público infantil e juvenil, serve também para apaziguar os sentimentos de quem passa pela dor da morte. Talvez as crianças sejam o caminho para que esses sentimentos tão obscuros ganhem novas formas e entendimentos. Como já disse José Saramago: "E se as histórias para crianças passassem a ser de leitura obrigatória para os adultos? Seriam eles capazes de aprender realmente o que há tanto tempo têm andado a ensinar? (SARAMAGO, 2001) 


\section{Referências Bibliográficas}

COUTO, Mia. O pátio das sombras. Ilustrações de Malangatana, vol. 10. In: Contos de Moçambique, São Paulo: Kapulana, 2018.

MESSIAS, Lázaro, (2008), Para Uma Teologia Africana : Missionação e Inculturação na África Lusófona, Lisboa: Prefácio, 2008.

SARAMAGO, José. A maior flor do mundo. Ilustrações de João Caetano, São Paulo: Companhia das Letrinhas, 2001. 